\title{
A Case of Lateral Neck Cyst with Ectopic Thyroid Papillary Carcinoma
}

\author{
Dr. Chhanda Das ${ }^{1}$, Dr. Madhumita Mukhopadhyay ${ }^{1}$, Dr. Moumita Sengupta ${ }^{1}$, \\ Dr. Ashis Kumar Saha ${ }^{2}$, Dr. Santanu Dutta ${ }^{3}$ \\ ${ }^{I}$ (Department of Pathology, IPGME\&R, Kolkata, India) \\ ${ }_{2}^{2}$ (Department of Surgery, Bankura Sammilani Medical College, Bankura, India) \\ ${ }^{3}$ (Department of Surgery, IPGME\&R, Kolkata, India)
}

\begin{abstract}
Thyroid develops from median rudiment which is a surface elevation dorsal to the tuberculam impar and forms by proliferation of endodermal cells. Lateral thyroid element of the fourth pouch contributes in the development of thyroid gland. Failure of the lateral thyroid element to fuse with the median element may result in a lateral ectopic thyroid gland. In the present case, patient initially presented with lateral neck cyst. There were two possibilities in the patient: a) a cystic degeneration of lymph node metastasis from an occult thyroid papillary carcinoma and b) thyroid papillary carcinoma arising from ectopic thyroid tissue within a branchial cleft cyst. Histological examination demonstrated foci of normal thyroid glands along with evidence of papillary thyroid carcinoma. These finding favours the possibility of malignant transformation of follicular epithelial cells of ectopic thyroid tissue within a branchial cleft cyst. There was a focus of papillary thyroid carcinoma in the resected total thyroidectomy specimen. So differentiation between two possibilities becomes difficult in this patient. A papillary thyroid carcinoma found with a cyst of the lateral neck represents a diagnostic and therapeutic dilemma.
\end{abstract}

Keywords: Ectopic Thyroid Tissue, Branchial Cleft Cyst, Papillary Thyroid Carcinoma.

\section{INTRODUCTION}

During embryogenesis, à number of developmental anomalies may occur in case of thyroid gland. Ectopic thyroid tissue is one of such developmental anomaly. We here present a rare case of papillary carcinoma of thyroid arising from ectopic thyroid follicular epithelium within a branchial cyst. Thyroid develops from median rudiment which is a surface elevation dorsal to the tuberculam impar and forms by proliferation of endodermal cells. After evagination from tongue substances, thyroglossal duct is formed. Thyroglossal duct disappears after formation of the isthmus and the lateral lobes of the thyroid. Lateral thyroid element of the fourth pouch contributes in the development of thyroid gland. Failure of the lateral thyroid element to fuse with the median element may result in a lateral ectopic thyroid gland. It is usually found along the course of thyroglossal duct. Other sites are larynx, trachea, mediastinum and pericardium. Incidence of ectopic thyroid lesion in adult is $7 \%{ }^{[1]}$.

Rarely branchial cyst demonstrates presence of ectopic thyroid tissue. Ectopic thyroid gland can develop similar benign and malignant pathological conditions as in the thyroid gland ${ }^{[2]}$. Ectopic thyroid tissue within a branchial cyst is rare. Metastatic papillary thyroid carcinoma in neck lymph nodes can undergo cystic degeneration. Approximately $40 \%$ of all lymph node metastases from papillary thyroid carcinomas have tendency to cavitate a lymph node by cystic degeneration completely ${ }^{[3]}$. This cystic lymph node can mimic branchial cleft cyst.

\section{CASE REPORT}

A 29 years old married female presented at ENT outdoor with the chief complaint of cough for three

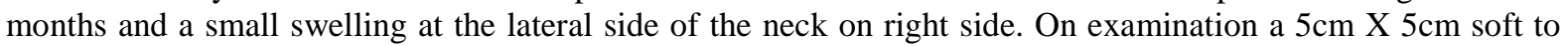
firm swelling on right side of the neck anterior to the sternocleidomastoid muscle was found below the angle of mandible. CT scan revealed large oval cystic lesion with high density contents (H.U. 29 to 40) within and nodular wall enhancement at right posterior cervical space displacing carotid sheath anteriorly favoring third branchial cleft cyst. FNAC was performed after clinical examination and proper consent. Predominantly degenerated RBC, few scattered non specific inflammatory cells and haemosiderin laden macrophages were seen under microscopic examination. Vascular tumor was considered.

Excision of the neck mass was done under general anesthesia. Gross examination showed $5 \mathrm{~cm} \mathrm{x} 3 \mathrm{~cm} \mathrm{x}$ $2 \mathrm{~cm}$ globular mass. The histology of the resected lesion demonstrated simple columnar epithelium lining of the cyst wall and foci of relatively normal thyroid glands. Papillary thyroid carcinoma with complex branching pattern was noted at places. High magnification showed typical features of optically clear nucleus with nuclear 
grooving and irregular nuclear contour. Immunohistochemical staining with thyroid transcription factor done. Nuclei of papilla of the ectopic thyroid papillary carcinoma showed positive staining but the lining epithelium of cyst wall is negative. Diagnosis of papillary thyroid carcinoma arising from ectopic thyroid tissue in branchial cyst was made.

Postoperative ultrasound of neck showed a hypo echoic small nodule with tiny foci of calcification in right lobe of thyroid $(0.9 \mathrm{~cm} \mathrm{X} 0.8 \mathrm{~cm})$ and a lymph node of size $(2.9 \mathrm{~cm} \mathrm{X} 1.2 \mathrm{~cm})$ in Rt. Jugulo-digastric region. Total thyroidectomy with lymph nodes removal was done in the patient. Histological examination of the resected thyroid gland revealed foci of papillary carcinoma of thyroid. Lymph nodes showed no metastatic deposit.

\section{DISCUSSION}

Ectopic thyroid lesion is found along the course of thyroglossal duct. The presence of ectopic thyroid tissue within the wall of a branchial cyst is caused by either incomplete obliteration of the pharyngeal pouches or embryonic thyroid epithelial inclusions within cervical lymph nodes, which trigger cystic degeneration ${ }^{[4-6]}$. In the present case, patient initially presented with lateral neck cyst. There were two possibilities in the patient: a) a cystic degeneration of lymph node metastasis from an occult thyroid papillary carcinoma and b) thyroid papillary carcinoma arising from ectopic thyroid tissue within a branchial cleft cyst. Histological examination demonstrated foci of normal thyroid glands along with evidence of papillary thyroid carcinoma. These finding favours the possibility of malignant transformation of follicular epithelial cells of ectopic thyroid tissue within a branchial cleft cyst.

According to Sidhu's report, a papillary carcinoma arising from ectopic thyroid tissue within a branchial cleft cyst should fulfill the following criteria: 1 . An epithelial lining layer, 2 . A subepithelial collection of lymphoid tissue typical of a branchial cleft cyst, 3 . Normal thyroid tissue within the cyst wall adjacent to the focus of papillary carcinoma, 4. Positive staining for TTF- I in tumor tissue, 5. No evidence of papillary carcinoma in the thyroid gland when it is removed and subjected to histological examination ${ }^{[7]}$.The present case meet all the criteria except the last one. In the present case, there was a focus of papillary thyroid carcinoma in the resected total thyroidectomy specimen. So differentiation between two possibilities becomes difficult in this patient. A papillary thyroid carcinoma found with a cyst of the lateral neck represents a diagnostic and therapeutic dilemma ${ }^{[8]}$. Thorough diagnostic work up is needed.

\section{Conclusion}

Papillary carcinoma of thyroid arising from ectopic thyroid follicular epithelium within a branchial cyst is rare. Histological examination is necessary apart from clinical and radiological investigations for this entity.
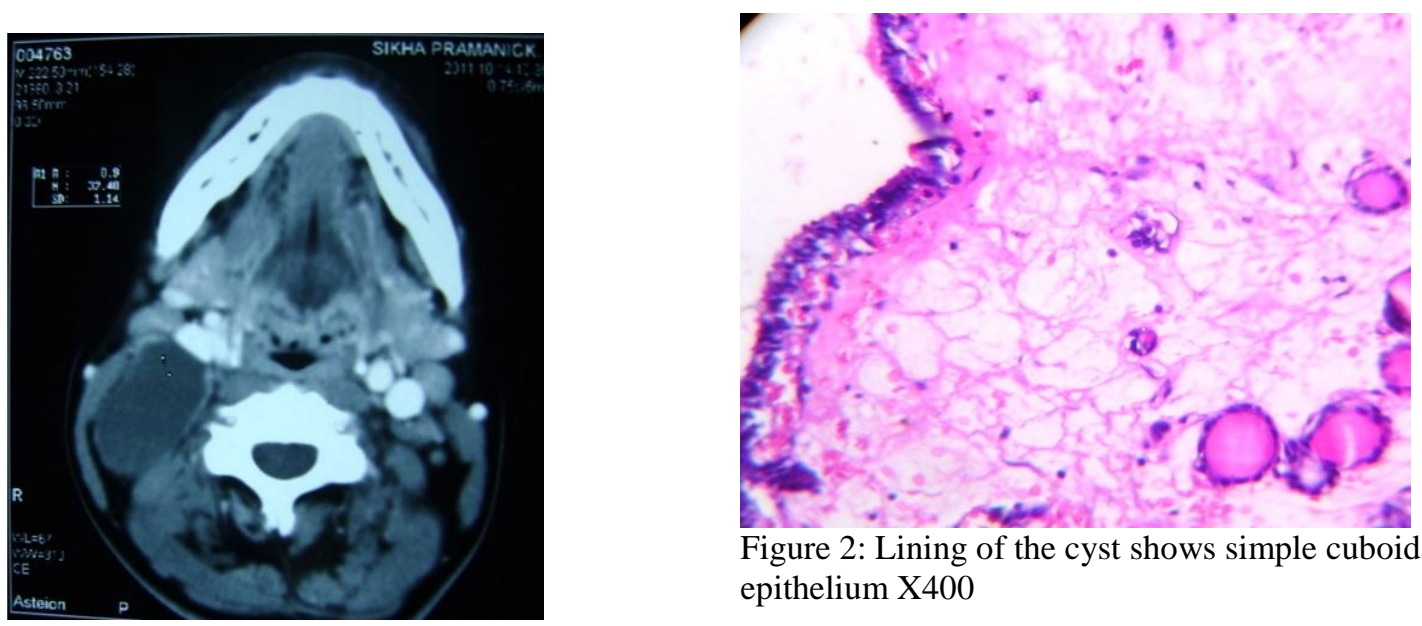

Figure 2: Lining of the cyst shows simple cuboidal epithelium X400

Figure 1: CT scan showing large oval cystic lesion 


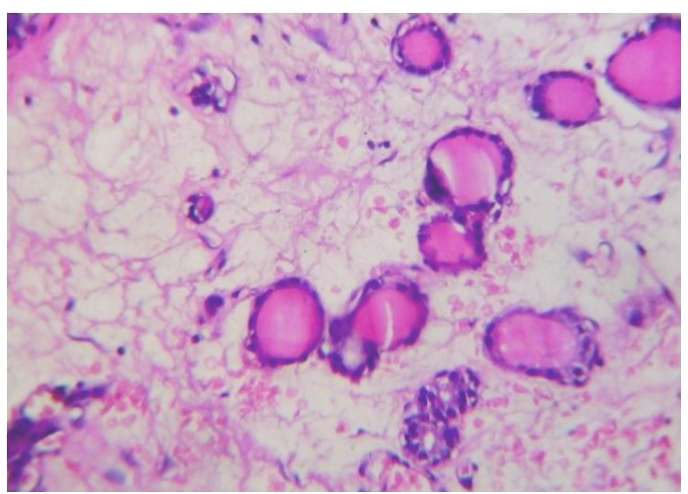

Figure 3: Foci of relatively normal thyroid glands $\mathrm{X} 400$

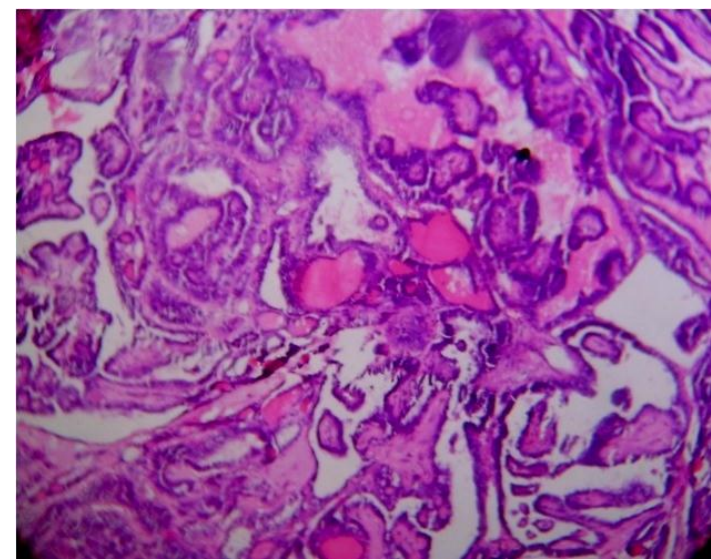

Figure 4: Foci of papillary thyroid carcinoma with complex branching pattern in the cyst X100

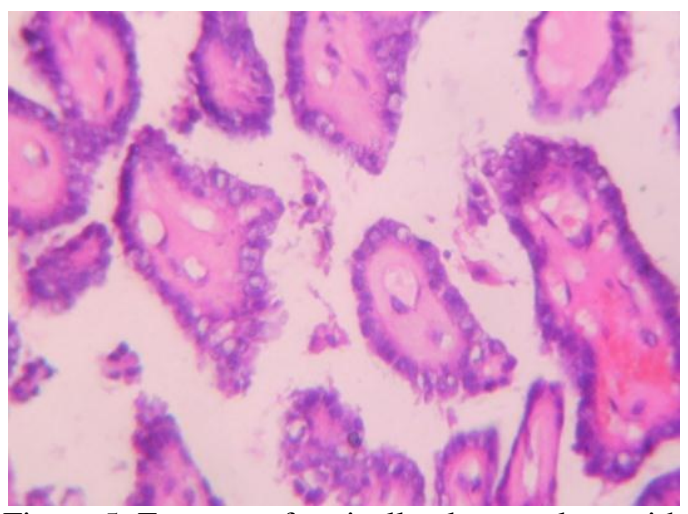

Figure 5: Features of optically clear nucleus with nuclear grooving and irregular nuclear contour

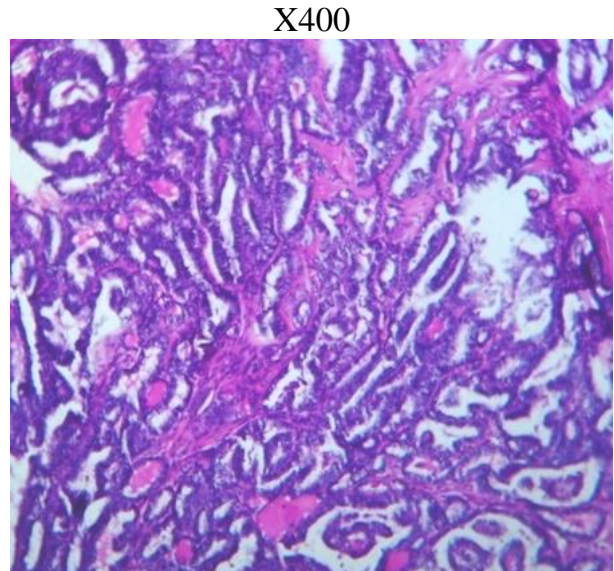

Figure 6: Foci of thyroid papillary carcinoma in thyroidectomy specimen $\mathrm{x} 100$

\section{References:}

[1] Yildiz K, Koksal H, Ozoran Y, Muhtar H, Telatar M, Papillary carcinoma in a thyroglossal duct remnant with normal thyroid gland. Laryngol Otol 1993, 107:1174-1176.

[2] De Felice M, Di Lauro R, Thyroid development and its disorders: genetics and molecular mechanisms. Endocr Rev 2004, 25:722746.

[3] King AD, Ahuja AT, To EW, Tse GM, Metreweli C, Staging papillary carcinoma of the thyroid: magnetic resonance imaging vs. ultrasound of the neck. Clin Radiol 2000, 55:222-6.

[4] Chionh EH, Pham VH, Cooke RA, and Gough IR, Aetiology of branchial cysts. Aust N Z J Surg, 1989, 59:949-951.

[5] Golledge J, and Ellis H, The aetiology of lateral cervical (branchial) cysts: past and present theories. J Laryngol Otol, 1994, 108:653-659.

[6] Wild G, Mischke D, Lobeck H, and Kastenbauer E, The lateral cyst of the neck: congenital or acquired? Acta Otolaryngol, 1987, 103:546-550.

[7] Sidhu S, Lioe TF, Clements B, Thyroid papillary carcinoma in lateral neck cyst: missed primary tumour or ectopic thyroid carcinoma within a branchial cyst? J Laryngol Otol, 2000, 114:716-718.

[8] Cappellani M, Di Vita, A Zanghi, Di Stefano, A case branchial cyst with an ectopic thyroid carcinoma: Ann Ital. Chir LXXV, 3. 2004 